Article

\title{
Clinical Implication of Preoperative C-Reactive Protein/Albumin Ratio in Malignant Transformation of Intraductal Papillary Mucinous Neoplasm: A Propensity Score Analysis
}

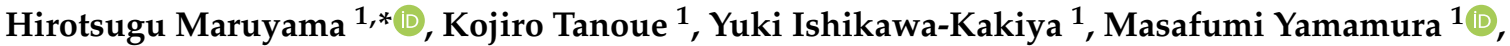 \\ Akira Higashimori ${ }^{1}$, Masaki Ominami ${ }^{1}$, Yuji Nadatani ${ }^{1}\left(\mathbb{D}\right.$, Shusei Fukunaga ${ }^{1}$, Koji Otani ${ }^{1}$ (D), Shuhei Hosomi ${ }^{1}(\mathbb{D}$, \\ Fumio Tanaka ${ }^{1}$, Noriko Kamata ${ }^{1}$, Yasuaki Nagami ${ }^{1}$, Koichi Taira ${ }^{1}{ }^{\mathbb{D}}$, Go Ohira ${ }^{2}$, Kenjiro Kimura ${ }^{2}$, \\ Ryosuke Amano $^{2}$ and Yasuhiro Fujiwara ${ }^{1}$
}

check for

updates

Citation: Maruyama, H.; Tanoue, K.; Ishikawa-Kakiya, Y.; Yamamura, M.; Higashimori, A.; Ominami, M.; Nadatani, Y.; Fukunaga, S.; Otani, K.; Hosomi, S.; et al. Clinical Implication of Preoperative C-Reactive

Protein/Albumin Ratio in Malignant Transformation of Intraductal Papillary Mucinous Neoplasm: A Propensity Score Analysis. Diagnostics 2022, 12, 554. https:// doi.org/10.3390/diagnostics12020554

Academic Editors: Keiji Hanada, Atsushi Kanno and Masahiro Serikawa

Received: 17 January 2022 Accepted: 17 February 2022 Published: 21 February 2022

Publisher's Note: MDPI stays neutral with regard to jurisdictional claims in published maps and institutional affiliations.

Copyright: (c) 2022 by the authors. Licensee MDPI, Basel, Switzerland. This article is an open access article distributed under the terms and conditions of the Creative Commons Attribution (CC BY) license (https:// creativecommons.org/licenses/by/ $4.0 /)$.
1 Department of Gastroenterology, Osaka City University Graduate School of Medicine, Osaka 545-8585, Japan; kojitane0622@yahoo.co.jp (K.T.); yukinaze010@hotmail.com (Y.I.-K.); y_masa0520@yahoo.co.jp (M.Y.); higamo@med.osaka-cu.ac.jp (A.H.); komesoudoh@yahoo.co.jp (M.O.); dada@med.osaka-cu.ac.jp (Y.N.); sfukunag0914@yahoo.co.jp (S.F.); kojiotani@med.osaka-cu.ac.jp (K.O.); m1265271@med.osaka-cu.ac.jp (S.H.); m2079981@med.osaka-cu.ac.jp (F.T.); nkamata@med.osaka-cu.ac.jp (N.K.); yasuaki-75@med.osaka-cu.ac.jp (Y.N.); koichit0802@gmail.com (K.T.); yasu@med.osaka-cu.ac.jp (Y.F.)

2 Department of Surgical Oncology, Osaka City University Graduate School of Medicine, Osaka 545-8585, Japan; m1153123@med.osaka-cu.ac.jp (G.O.); kenjirokimura@hotmail.com (K.K.); ramano@med.osaka-cu.ac.jp (R.A.)

* Correspondence: m2036423@med.osaka-cu.ac.jp or hiromaruyama99@gmail.com; Tel.: +81-6645-3811

Abstract: Background: Inflammation-based scoring has been reported to be useful for predicting the recurrence and prognosis of various carcinomas. This study retrospectively investigated the relationship between inflammation-based score and intraductal papillary mucinous neoplasms (IPMNs). Methods: Between January 2013 and October 2018, we enrolled 417 consecutive patients with pancreatic tumors who received surgical resections at our hospital. The main outcome was the association between the preoperative inflammation-based score and their accuracy in predicting malignant transformation of IPMN. Results: Seventy six patients were eligible. Pathological findings indicated that 35 patients had low-grade dysplasia, 18 had high-grade dysplasia, and 23 had invasive carcinomas. As the $\mathrm{C}$-reactive protein albumin ratio (CAR) was higher, malignant transformation of IPMNs also increased ( $p=0.007)$. In comparing $C A R^{\text {high }}$ and $C A R^{\text {low }}$ using cutoff value, the results using a propensity score analysis showed that the $C A R^{\text {high }}$ group predicted malignant transformation of IPMNs (odds ratio, 4.18 ; 95\% confidence interval, $1.37-12.8 ; p=0.01$ ). In the CAR ${ }^{\text {high }}$ group, diseasefree survival (DFS) was significantly shorter $(p=0.04)$. In the worrisome features, the AUC for the accuracy of malignant transformation with $\mathrm{CAR}^{\text {high }}$ was 0.84 when combining with the MPD findings. Conclusions: Preoperative CAR could be a predictive marker of malignant transformation of IPMNs.

Keywords: intraductal papillary mucinous neoplasm; inflammation-based score; C-reactive protein albumin ratio; malignant transformation

\section{Introduction}

Intraductal papillary mucinous neoplasms (IPMNs) are the most frequent pancreatic cystic neoplasms with malignant potential [1,2]. Recently, there has been an increase in IPMN diagnoses due to the enhanced accuracy of images and recognition of the disease [3]. However, the inability to determine the benign or malignant nature of IPMN based on image findings creates a clinical problem.

In 2017, the IPMN International Consensus Guidelines were revised [4]. The factors of high-risk stigmata (HRS) and worrisome features (WF) were changed, and a "mural nodule (MN) size of $5 \mathrm{~mm}$ or more" was specified. Additionally, according to the guidelines, 
the indications for surgery are HRS (obstructive jaundice, enhancing MN $\geq 5 \mathrm{~mm}$, main pancreatic duct $(\mathrm{MPD}) \geq 10 \mathrm{~mm}$ ). However, postoperative histopathological findings often show adenoma rather than cancer, and the diagnostic disagreements between preoperative imaging findings and postoperative histopathological findings are problematic [5-7].

Clinically, IPMNs tend to be over-treated with surgery. On the other hand, invasive cancer has a poor prognosis, and it is important to carefully judge the indication for surgery. Furthermore, there are cases where cancer is present and cases where the transition to invasive examination such as endoscopic retrograde cholangiopancreatography (ERCP) is needed in the WF $[8,9]$. These cases need very careful follow-up. At present, image findings and tumor markers alone have limitations. Therefore, novel biomarkers with simple and higher accuracy for predicting the presence of malignancy are needed.

Systemic inflammatory reactions are used as biomarkers, as they play a crucial role in the malignant transformation and progression of various solid tumors [10-14]. The existence of systemic inflammation, as measured by parameters such as neutrophil-tolymphocyte ratio (NLR), Glasgow Prognostic Score (GPS), C-reactive protein albumin ratio (CAR), and lymphocyte-to-monocyte ratio (LMR), are associated with poor prognosis across multiple malignancies, including pancreatic cancer [15,16]. Recently, NLR and PLR have been reported to be predictive markers for the presence of invasive carcinoma in pancreatic cysts $[13,17]$. However, the relationship with inflammation-based scores in the patients with IPMNs has rarely been reported [17-19]. Therefore, we hypothesized that preoperative values of the preoperative inflammation-based scores are predictive factors for malignant transformation of IPMNs.

The aim of study was to investigate the relationship between preoperative the preoperative inflammation-based scores and the malignant transformation of IPMNs.

\section{Materials and Methods}

\subsection{Patients}

This research was a retrospective cohort study performed at a single referral hospital. Between January 2013 and October 2018, 417 consecutive patients with pancreatic tumors underwent surgical resection at the Department of Surgical Oncology, Osaka City University Graduate School of Medicine. In addition, clinical information on postoperative histopathological findings was collected retrospectively from electronic medical records. The inclusion criteria were IPMN, low-grade dysplasia (LGD), high-grade dysplasia (HGD), or invasive carcinoma (INV). The exclusion criteria were as follows: (i) pancreatic ductal adenocarcinoma (PDAC) (including IPMN with PDAC), (ii) bile duct cancer, (iii) neuroendocrine tumor, (iv) solid-pseudopapillary neoplasm, (v) metastatic pancreatic tumor, (vi) mucinous cystic neoplasm, (vii) serous cystic neoplasm, (viii) benign disease (pseudo pancreatic cyst, chronic pancreatitis, and pancreaticobiliary maljunction).

\subsection{Ethical Considerations}

The ethics committee of the Osaka City University Graduate School of Medicine approved the study's protocol (number 4342). In addition, we provided all patients with the opportunity to opt out of the study on our website's home page.

\subsection{Main Outcome Measurements}

We investigated whether the preoperative value of the preoperative inflammationbased scores is useful for predicting malignant transformation of IPMN.

\subsection{Data Collection}

Clinical patient data were collected as follows: age, sex, IPMN type (Main duct type, Mixed type, Branch duct type), number of cysts (Unifocal, Multifocal), operation procedure, tumor location, size of cyst, MPD diameter, presence of MN, presence of jaundice, and history of pancreatitis. Preoperative neutrophil count, lymphocyte count, platelet count, monocyte count, high-sensitivity C-reactive protein (CRP), albumin, jaundice, 
carcinoembryonic antigen (CEA), and carbohydrate antigen 19-9 (CA19-9) were collected from the blood samples within seven days before surgery. The inflammation-based scores, including NLR, CAR, LMR were examined using those samples. We defined the normal range of CEA and CA19-9 as 0 to $5 \mathrm{ng} / \mathrm{mL}$ and 0 to $37 \mathrm{U} / \mathrm{mL}$, respectively, at our hospital.

\subsection{Histopathological Assessment}

The resected specimens were evaluated according to criteria defined by a recent consensus. The histological grade of IPMN was evaluated as LGD, HGD, or INV [20].

\subsection{Imaging Assessment}

We evaluated IPMN type, number of cysts, tumor location, size of cyst, MPD diameter, and presence of $\mathrm{MN}$ based on available imaging data from endoscopic ultrasonography (EUS) and/or computed tomography (CT)/magnetic resonance imaging (MRI).

\subsection{Endoscopic Procedure}

We used echoendoscope (GF-UCT260, GF-UCT240, and GF-UE260; Olympus Medical System, Tokyo, Japan) and ultrasound processer (Aloka ProSound $\alpha 5$ and F75) under conscious sedation for all patients. Both trainees and experts performed EUS, because our hospital is a teaching hospital. Trainees were assisted by experts as needed to ensure procedural quality when performing EUS.

\subsection{Imaging Acquisition}

Contrast-enhanced CT examination was performed with multi-detector CT machines. Arterial phase scanning began 35-40 s after injection of $2 \mathrm{~mL} / \mathrm{kg}$ of body weight of a nonionic iodinated contrast agent at a rate of $4 \mathrm{~mL} / \mathrm{s}$ with a bolus-triggered technique using an automatic power injector. Portal and delayed phase scanning were begun 70 and $180 \mathrm{~s}$ after the start of the contrast medium injection, respectively. The slice thickness was $2 \mathrm{~mm}$ or $5 \mathrm{~mm}$.

The MRI examination was performed using a 3.0 Tesla system (Ingenia; Philips Healthcare, Best, The Netherlands). MRI images were acquired using the following sequences: a T1 weighted sequence (in-phase and out-of-phase), T2 weighted sequence, FAT-SAT sequence, diffusion-weighted sequence, magnetic resonance cholangiopancreatography.

\subsection{Statistical Analysis}

To summarize baseline patients' clinical and demographical characteristics, medians and interquartile ranges were used for continuous variables and percentages, and counts were used for categorical variables. Regarding the categorical variables, comparisons were performed using the chi-squared test or Fisher's exact test when necessary, because of the small sample sizes. For the continuous variables, comparisons were performed using Student's $t$-test. The Jonckheere-Terpstra test was used to analyze the tendency of the systemic inflammation markers and three groups (LGD, HGD and INV). The diagnostic accuracy, including sensitivity, specificity, and accuracy, was calculated for each parameter using the cutoff values determined by the receiver operating characteristic (ROC) curve analysis. The cutoff values were defined as the highest sensitivity and specificity that lay closest to the left upper corner of the ROC curve. First, binary logistic regression analysis was used to evaluate the predictive factors for the presence of HGD and INV, estimated by calculating the odds ratios (ORs) and the 95\% confidence intervals (CIs). Secondly, to evaluate the association between the CAR and IPMN with LGD and HGD/INV, the multivariable regression model was used with adjustments for age, sex, presence of $\mathrm{MN}$, MPD $\geq 10 \mathrm{~mm}$, and the presence of jaundice. In this model, a nonlinear restricted cubic spline was drawn to allow a nonlinear determination for normalization of the CAR on IPMN with LGD and HGD/INV along with adjustment for the set of covariates described above. All statistical inferences were performed using two-sided testing at the $5 \%$ significance level. All statistical analyses were conducted with $\mathrm{R}$ software version 3.6.1. 
In addition, the inverse probability of treatment weighting (IPTW) method was applied to assess the predictive factors of IPMN with HGD/INV. This method can adjust for confounding factors and evaluate causal effects without reducing sample size using the estimated propensity scores to assign weights to the data. Statistical analyses were performed using IBM SPSS software, version 23.0 for Windows (IBM Corp., Armonk, NY, USA).

\section{Results}

\subsection{Baseline Characteristics of Patients}

A total 76 patients with histopathological diagnosed IPMN were included in this study (Figure 1). Patient clinicopathological characteristics of this study subject are shown in Table 1 . The median age was 73 years (range 69-76), the proportion of males was $61 \%$, and the median CAR was 0.02 (range 0.006-0.09). Regarding histological grade, 35 patients (46\%) had LGD, 18 (23.6\%) had HGD, and 23 (30.4\%) had invasive INV. Some patients had a history of other organ cancer; however, there were no recurrences, and none were receiving chemotherapy or radiation therapy. In the comparison between the LGD group and the HGD / INV group, WF was significantly higher in the LGD group $(p=0.01)$, and CAR tended to be higher in the HGD/INV group $(p=0.06)$. CA19-9 showed a significant difference; however, most cases were within the normal range.

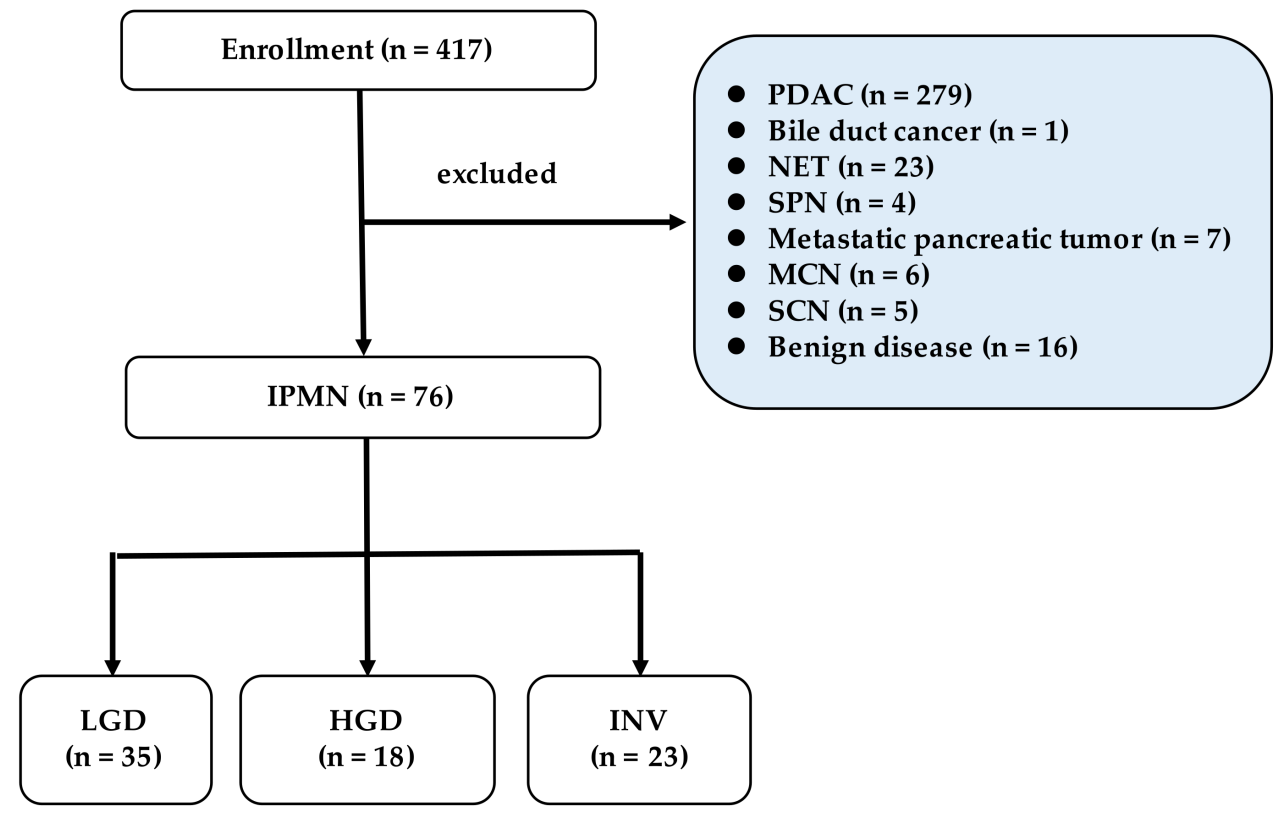

Figure 1. Diagram illustrating the study design. PDAC: pancreatic ductal adenocarcinoma, NET: neuroendocrine tumor, SPN: solid-pseudopapillary neoplasm, MCN: mucinous cystic neoplasm, SCN: serous cystic neoplasm, IPMN: intraductal mucinous neoplasm, LGD: low-grade dysplasia, HGD: high-grade dysplasia, INV: invasive carcinoma.

\subsection{Preoperative Inflammation-Based Scores}

We focused on each marker to differentiate IPMN with HGD and INV from IPMN with LGD in terms of the surgical indication. Figure 2 shows that the CAR of IPMN with HGD and INV were higher than that of IPMN with LGD $(p=0.007)$. No significant difference was found between NLR, PLR, and LMR. In addition, the higher the grade (HGD and INV) in the multivariable regression model with restricted cubic spline, the higher the CAR, and it was positively correlated $(p=0.047)$. The analysis showed that a higher CAR would increase the malignant transformation of IPMN. According to this result, we focused on CAR and calculated the cutoff value from the ROC curve as 0.011 (Figure 3). 
Table 1. Patient clinicopathological characteristics.

\begin{tabular}{|c|c|c|c|c|c|}
\hline & & Total & LGD & HGD and INV & $p$-Value \\
\hline Patients, n. (\%) & & $76(100)$ & $35(46)$ & $41(54)$ & \\
\hline Age, median (IQR), years & & $73(69-76)$ & $73(68.5-75.5)$ & $73(71.0-76.0)$ & 0.71 \\
\hline \multirow[t]{2}{*}{ Sex, n. $(\%)$} & Male & $46(61)$ & $23(65.7)$ & $23(56.1)$ & 0.48 \\
\hline & Female & $30(39)$ & $12(34.3)$ & $18(43.9)$ & \\
\hline \multirow[t]{3}{*}{ IPMN type, n. (\%) } & Main duct type & $8(10.5)$ & $2(5.7)$ & $6(14.7)$ & 0.48 \\
\hline & Mixed type & $32(42.1)$ & $16(45.7)$ & $16(39.0)$ & \\
\hline & $\begin{array}{c}\text { Branch duct } \\
\text { type }\end{array}$ & $36(47.4)$ & $17(48.6)$ & $19(46.3)$ & \\
\hline \multirow[t]{2}{*}{ Location, n. (\%) } & Head & $45(59)$ & $24(68.6)$ & $21(51.2)$ & 0.16 \\
\hline & Body or tail & $31(41)$ & $11(31.4)$ & $20(49.8)$ & \\
\hline \multirow[t]{2}{*}{ Number of cyst lesion, n. (\%) } & Unifocal & $54(71.1)$ & $24(68.5)$ & $30(73.2)$ & 0.79 \\
\hline & Multifocal & $22(28.9)$ & $11(31.5)$ & $11(26.8)$ & \\
\hline Cyst size (mm), median (IQR) & & $22.9(16.9-32.6)$ & $26.0(20.5-31.5)$ & $21.7(14.7-37.6)$ & 0.21 \\
\hline MPD diameter (mm), median (IQR) & & $5.45(3.8-8.35)$ & $5.5(3.4-8.4)$ & $5.4(3.9-8.3)$ & 0.76 \\
\hline Mural nodule (mm), median (IQR) & & $5.65(0-8.58)$ & $4.9(0-7.4)$ & $6.2(0-11.6)$ & 0.08 \\
\hline Jaundice, n. $(\%)$ & & $5(6.6)$ & $1(2.9)$ & $4(9.8)$ & 0.37 \\
\hline History of pancreatitis, n. (\%) & & $9(11.8)$ & $2(5.7)$ & $7(17)$ & 0.17 \\
\hline Worrisome features, n. (\%) & & $23(30.2)$ & $16(45.7)$ & $7(17)$ & 0.01 \\
\hline High-risk stigmata, n. (\%) & & $48(63.2)$ & $18(51.4)$ & $30(73.2)$ & 0.06 \\
\hline CEA, ng $/ \mathrm{mL}$, median (IQR) & & $3.2(1.9-5.3)$ & $3.0(1.7-4.75)$ & $3.3(2.3-5.3)$ & 0.48 \\
\hline CA19-9, IU/mL, median (IQR) & & $8(5-19.5)$ & $5.0(4.0-13)$ & $13(7.0-24)$ & 0.02 \\
\hline NLR, median (IQR) & & $2.3(1.6-3.72)$ & $2.54(1.58-3.90)$ & $2.32(1.66-3.27)$ & 0.87 \\
\hline LMR, median (IQR) & & $3.9(2.7-5.1)$ & $3.61(2.85-5.36)$ & $3.86(3.04-5.03)$ & 0.67 \\
\hline PLR, median (IQR) & & $84.5(59.3-123.8)$ & $83(58.5-140)$ & $86(65-107)$ & 0.56 \\
\hline CAR, median (IQR) & & $0.02(0.006-0.09)$ & $0.01(0.005-0.05)$ & $0.03(0.01-0.09)$ & 0.06 \\
\hline \multirow[t]{4}{*}{ Operation procedure, n. (\%) } & PD & $40(52.6)$ & $20(57.1)$ & $20(48.7)$ & \\
\hline & DP & $31(40.8)$ & $14(40)$ & $17(41.5)$ & \\
\hline & $\mathrm{TP}$ & $3(3.9)$ & $1(2.9)$ & $2(4.9)$ & \\
\hline & MP & $2(2.7)$ & 0 & $2(4.9)$ & \\
\hline
\end{tabular}

IQR: interquartile range, IPMN: intraductal mucinous neoplasm, MPD: main pancreatic duct, CEA: carcinoembryonic antigen, CA19-9: carbohydrate antigen, NLR: neutrophil-to-lymphocyte ratio, LMR: lymphocyte-to-monocyte ratio, PLR: platelet-lymphocyte ratio, CAR: C-reactive protein albumin ratio, PD: pancreaticoduodenectomy, DP: distal pancreatectomy, TP: total pancreatectomy MP: middle pancreatectomy, LGD: low grade dysplasia, HGD: high grade dysplasia, INV: invasive carcinoma.
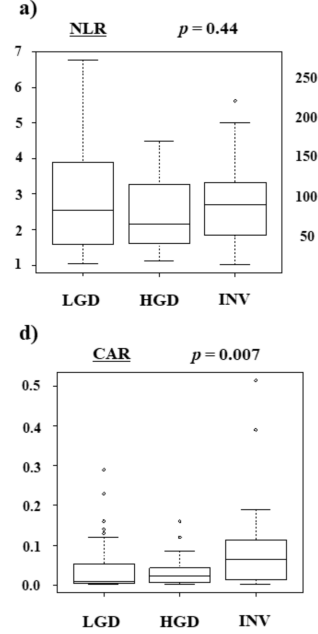

b) $\quad \underline{\text { PLR }} \quad p=0.60 \quad$ c)
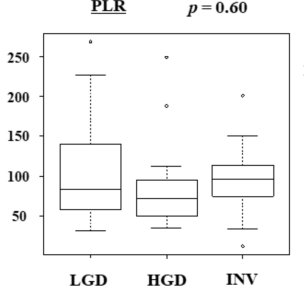

e)

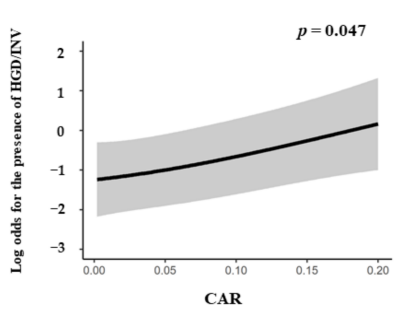

Figure 2. The association between the preoperative inflammation-based scores and 3 subgroups (LDG, HGD and INV). (a) NLR. (b) PLR. (c) LMR. (d) CAR. (e) The analysis was positively correlated $(p=0.047)$ and showed that a higher CAR would increase the malignant transformation of IPMN. IPMN: intraductal mucinous neoplasm. NLR: neutrophil-to-lymphocyte ratio, PLR: plateletlymphocyte ratio, LMR: lymphocyte-to-monocyte ratio, CAR: C-reactive protein albumin ratio, LGD: low grade dysplasia, HGD: high grade dysplasia, INV: invasive carcinoma. 


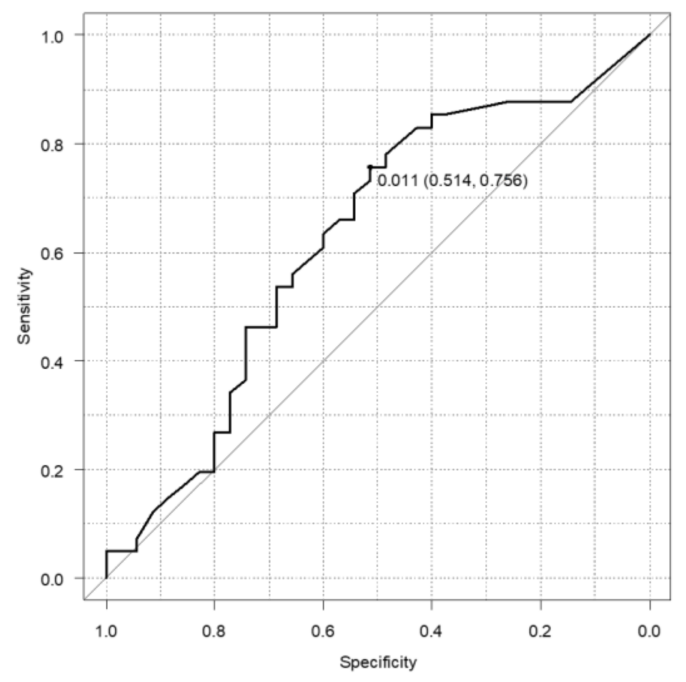

Figure 3. ROC curve of CAR. The cutoff was calculated 0.011 from the ROC curve. ROC: receiver operating characteristic, CAR: C-reactive protein albumin ratio.

\subsection{Clinical Outcome}

We divided the patients into two groups, $C A R^{\text {low }}$ and $C A R^{\text {high }}$, according to the optimal cutoff value of CAR (0.011). Compared with patients of the CAR ${ }^{\text {low }}$ group, patients of $C A R^{\text {high }}$ group were no significant differences in age, sex, IPMN type, cyst size, MPD diameter, MN, and LMR. However, CEA and PLR were significantly higher in the CAR ${ }^{\text {low }}$ group (Table 2). Univariate and multivariate analyses for predictive factors of IPMN with HGD/INV are shown in Table 3. Predictive factors of IPMN with HGD/INV in the univariate analysis was $\mathrm{CAR}^{\text {high }}(\mathrm{OR}, 3.28$; 95\% confidence interval [CI], $1.24-8.69 ; p=0.02)$ and $\geq 5 \mathrm{~mm}$ contrast $\mathrm{MN}$ (OR, 6.18; 95\% CI, 2.11-18.1; $p<0.01)$. Similar results were indicated in multivariate analysis (CAR ${ }^{\text {high }} ; \mathrm{OR}, 3.84 ; 95 \% \mathrm{CI}, 1.28-11.5 ; p=0.02, \geq 5 \mathrm{~mm}$ contrast MN; OR, 5.38; 95\% CI, 1.71-16.9; $p<0.01$ ) (Table 3).

Table 2. Comparison of clinical characteristics between $\mathrm{CAR}^{\text {low }}$ and $C A R^{\text {high }}$.

\begin{tabular}{|c|c|c|c|c|c|}
\hline & & Total & CAR $^{\text {low }}$ & CAR $^{\text {high }}$ & $p$-Value \\
\hline Patients, n. (\%) & & 76 & $28(36.8)$ & $48(63.2)$ & \\
\hline Age, median (IQR), years & & $73(69-76)$ & $73(65.5-76.0)$ & $73(69-75.3)$ & 0.74 \\
\hline \multirow{2}{*}{ Sex, n. $(\%)$} & Male & $46(60.5)$ & $16(57.1)$ & $30(62.5)$ & 0.81 \\
\hline & Female & $30(39.5)$ & $12(42.9)$ & $18(37.5)$ & \\
\hline \multirow{2}{*}{ IPMN type, n. (\%) } & Branch duct type & $40(52.6)$ & $13(46.4)$ & $27(56.2)$ & 0.48 \\
\hline & Mixed, Main duct type & $36(47.4)$ & $15(53.6)$ & $11(43.8)$ & \\
\hline \multirow{2}{*}{ Location, n. (\%) } & Head & $45(59.2)$ & $15(53.6)$ & $30(62.5)$ & 0.48 \\
\hline & Body or tail & $31(40.8)$ & $13(46.4)$ & $18(37.5)$ & \\
\hline \multirow{2}{*}{ Number of cyst lesion, n. (\%) } & Unifocal & $54(71.1)$ & $18(64.3)$ & $36(75)$ & 0.4 \\
\hline & Multifocal & $22(28.9)$ & $10(35.7)$ & $12(25)$ & \\
\hline \multirow{2}{*}{ Cyst size (mm), n. (\%) } & $<30$ & $52(68.4)$ & $20(71.4)$ & $32(66.7)$ & 0.8 \\
\hline & $\geq 30$ & $24(31.6)$ & $8(28.6)$ & $16(33.3)$ & \\
\hline \multirow{2}{*}{ MPD diameter (mm), n. (\%) } & $<10$ & $59(77.6)$ & $24(85.7)$ & $35(72.9)$ & 0.26 \\
\hline & $\geq 10$ & $17(22.4)$ & $4(14.3)$ & $13(27.1)$ & \\
\hline Mural nodule, median (IQR), mm & & $5.65(0-8.78)$ & $5.85(0-7.78)$ & $5.45(0-9.45)$ & 0.86 \\
\hline$\geq 5 \mathrm{~mm}$ contrast mural nodule, $\mathrm{n} .(\%)$ & Present & $29(38.2)$ & $9(32.1)$ & $20(41.7)$ & 0.47 \\
\hline Jaundice, n. $(\%)$ & yes & $5(6.6)$ & $0(0)$ & $5(10.4)$ & 0.15 \\
\hline History of pancreatitis, n. (\%) & yes & $9(11.8)$ & $3(10.7)$ & $6(12.5)$ & 1 \\
\hline Worrisome features, n. (\%) & yes & $23(30.3)$ & $1139.3)$ & $12(25)$ & 0.21 \\
\hline High-risk stigmata, n. (\%) & yes & $48(63.2)$ & $17(60.7)$ & $31(64.6)$ & 0.81 \\
\hline
\end{tabular}


Table 2. Cont.

\begin{tabular}{|c|c|c|c|c|c|}
\hline & & Total & CAR $^{\text {low }}$ & CAR high & $p$-Value \\
\hline \multirow{2}{*}{ CEA, ng/mL, n. (\%) } & $\leq 5$ & $55(72.4)$ & $25(89.3)$ & $30(62.5)$ & \multirow[t]{2}{*}{0.02} \\
\hline & $>5$ & $21(27.6)$ & $3(10.7)$ & $18(37.5)$ & \\
\hline \multirow{2}{*}{ CA19-9, IU/mL, n. (\%) } & $\leq 37$ & $65(85.5)$ & $25(89.3)$ & $40(83.3)$ & \multirow[t]{2}{*}{0.74} \\
\hline & $>37$ & $11(14.5)$ & $3(10.7)$ & $8(16.7)$ & \\
\hline \multirow{2}{*}{ NLR, n. (\%) } & $<3.27$ & $51(67.1)$ & $22(78.6)$ & $29(60.4)$ & \multirow[t]{2}{*}{0.13} \\
\hline & $\geq 3.27$ & $25(32.9)$ & $6(21.4)$ & $19(39.6)$ & \\
\hline \multirow{2}{*}{ LMR, n. (\%) } & $<2.64$ & $11(14.5)$ & $3(10.7)$ & $8(16.7)$ & \multirow[t]{2}{*}{0.74} \\
\hline & $\geq 2.64$ & $65(85.5)$ & $25(89.3)$ & $40(83.3)$ & \\
\hline \multirow{2}{*}{ PLR, n. (\%) } & $<107$ & $50(65.8)$ & $23(82.1)$ & $27(56.3)$ & \multirow[t]{2}{*}{0.03} \\
\hline & $\geq 107$ & $26(34.2)$ & $5(17.9)$ & $21(43.7)$ & \\
\hline
\end{tabular}

IQR: interquartile range, IPMN: intraductal mucinous neoplasm, MPD: main pancreatic duct, CEA: carcinoembryonic antigen, CA19-9: carbohydrate antigen, NLR: neutrophil-to-lymphocyte ratio, LMR: lymphocyte-to-monocyte ratio, PLR: platelet-lymphocyte ratio, CAR: C-reactive protein albumin ratio.

Table 3. Predictive factors for IPMN with HGD/INV.

\begin{tabular}{|c|c|c|c|c|}
\hline & \multicolumn{2}{|c|}{ Univariate } & \multicolumn{2}{|c|}{ Multivariate } \\
\hline & OR $(95 \% \mathrm{CI})$ & $p$-Value & OR $(95 \% \mathrm{CI})$ & $p$-Value \\
\hline Age, years & $1.02(0.95-1.00)$ & 0.66 & & \\
\hline Sex, male (vs. female) & $0.67(0.26-1.69)$ & 0.39 & & \\
\hline IPMN type, Branch duct type (vs. Main duct and Mixed type) & $0.94(0.37-2.26)$ & 0.85 & & \\
\hline Location, Head (vs. body and tail) & $0.48(0.19-1.23)$ & 0.13 & & \\
\hline Cyst size (mm), <30 (vs. $\geq 30)$ & $0.99(0.97-1.02)$ & 0.76 & & \\
\hline Number of cyst lesion, Multifocal (vs. Unifocal) & $0.91(0.36-2.3)$ & 0.85 & & \\
\hline MPD diameter $(\mathrm{mm}), \geq 10$ (vs. $<10)$ & $1.29(0.43-3.85)$ & 0.65 & & \\
\hline Jandice, yes (vs. no) & $3.68(0.39-34.5)$ & 0.26 & & \\
\hline History of pancreatitis, yes (vs. no) & $3.40(0.66-17.6)$ & 0.15 & & \\
\hline Mural nodule, present (vs. absent) & $2.3(0.88-5.99)$ & 0.09 & & \\
\hline$\geq 5$ Contrast mural nodule, present (vs. absent) & $6.18(2.11-18.1)$ & $<0.01$ & $5.38(1.71-16.9)$ & $<0.01$ \\
\hline CEA $(\mathrm{ng} / \mathrm{mL}),>5($ vs. $\leq 5)$ & $1.2(0.43-3.29)$ & 0.73 & & \\
\hline CA19-9 (IU/mL), >37 (vs. $\leq 37)$ & $1.03(0.28-3.71)$ & 0.97 & & \\
\hline $\mathrm{NLR}, \geq 3.27(<3.27)$ & $0.55(0.21-1.45)$ & 0.23 & & \\
\hline LMR, $\geq 2.64($ vs. $<2.64)$ & $3.75(0.91-15.5)$ & 0.07 & $3.10(0.65-14.9)$ & 0.16 \\
\hline PLR, $\geq 107$ (vs. $<107)$ & $0.49(0.19-1.28)$ & 0.15 & & \\
\hline CAR, high (vs. low) & $3.28(1.24-8.69)$ & 0.02 & $3.84(1.28-11.5)$ & 0.02 \\
\hline
\end{tabular}

HGD: high grade dysplasia, INV: invasive carcinoma, IPMN: intraductal mucinous neoplasm, MPD: main pancreatic duct, CEA: carcinoembryonic antigen, CA19-9: carbohydrate antigen, NLR: neutrophil-to-lymphocyte ratio, LMR: lymphocyte-to-monocyte ratio, PLR: platelet-lymphocyte ratio, CAR: C-reactive protein albumin ratio, OR: odd ratio, CI: confidence interval.

In addition, after adjustment for confounding factors using IPTW, CAR ${ }^{\text {high }}$ was also predictive of IPMN with HGD/INV (OR, 4.18; 95\% CI, 1.37-16.8; $p=0.01$ ) (Table 4).

Table 4. IPTW logistic odds ratio of IPMN with HGD/INV for CAR ${ }^{\text {high }}$.

\begin{tabular}{ccc}
\hline & $\begin{array}{c}\text { Odds Ratio } \\
\mathbf{( 9 5 \% ~ C I ) ~}\end{array}$ & $p$-Value \\
\hline Unadjusted & $3.28(1.24-8.69)$ & 0.02 \\
Adjusted for contrast mural nodule, LMR $\geq 2.64$ & $3.84(1.28-11.5)$ & 0.02 \\
IPTW & $4.18(1.37-12.8)$ & 0.01 \\
IPTW adjusted for contrast mural nodule, LMR $\geq 2.64$ & $4.80(1.37-16.8)$ & 0.01
\end{tabular}

LMR: lymphocyte-to-monocyte ratio, IPTW: inverse probability of treatment weighting, CI: Confidence interval.

\subsection{Association of the CAR with Overall Survival and Disease-Free Survival}

The median follow-up period for all patients was 879.5 days (95\% CI 503.8-1232.8 days); disease recurred in $11(14.5 \%)$ patients, and $8(10.5 \%)$ patients died. 
In comparisons of $C A R^{\text {high }}$ and $C A R^{\text {low }}$, no significant difference was shown in OS $\left(C A R^{\text {high }}\right.$ vs. $C A R^{\text {low }} ; 1733.5$ vs. 1771.3 days, $p=0.89$ ). However, CAR $^{\text {high }}$ was significantly shorter in DFS (1550.7 vs. 1902.8 days, $p=0.04$ ) (Figure 4 ).

A

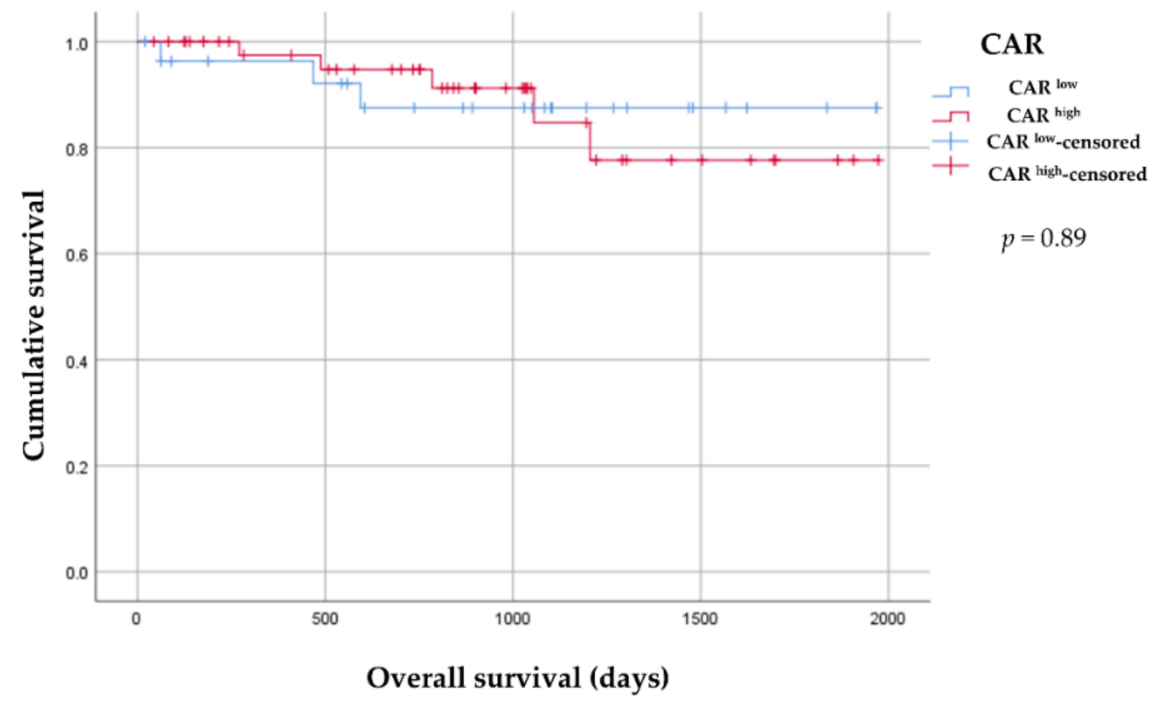

B

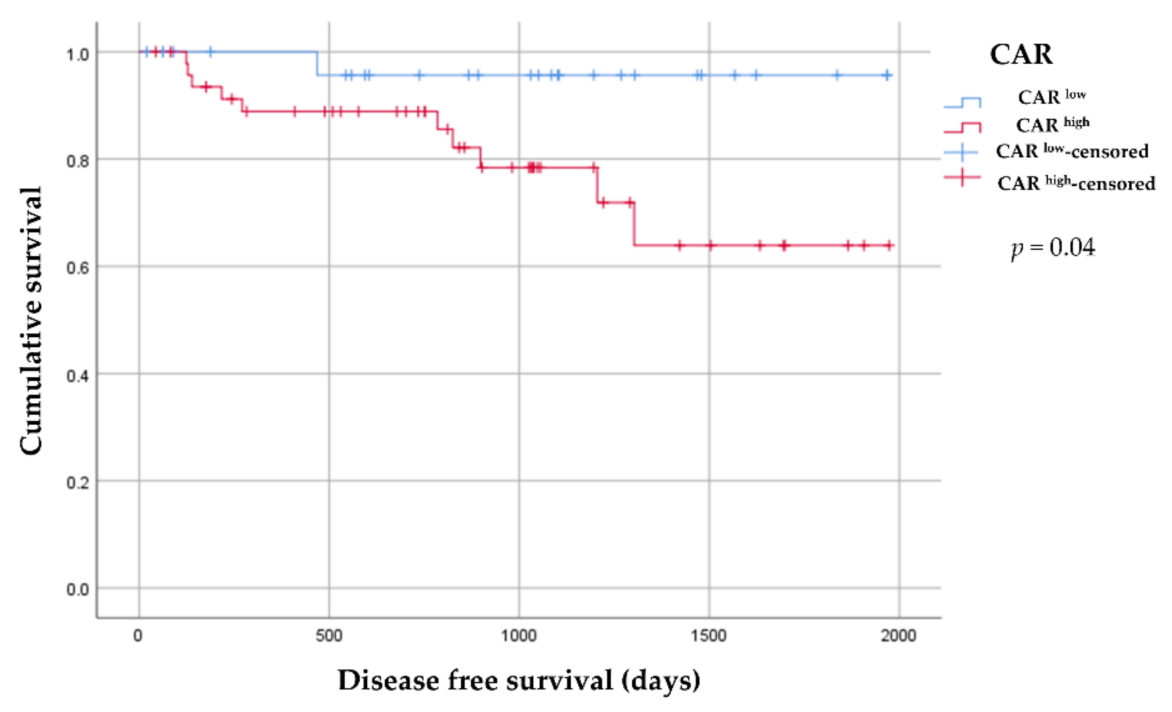

Figure 4. Kaplan-Meier survival curves. (A) Overall survival (OS). (B) Disease free survival (DFS). Kaplan-Meier survival curves showing the difference between the CAR ${ }^{\text {high }}$ and $C A R^{\text {low }}$ groups in DFS. OS showed no significant difference; however, $\mathrm{CAR}^{\text {high }}$ group was significantly shorter in DFS.

\subsection{Diagnostic Accuracy of CAR for WF Patients with HGD/INV}

We investigated the accuracy of HGD/INV diagnosis for each item of CAR ${ }^{\text {high }}$ and WF for $23 \mathrm{WF}$ patients using ROC curve analysis. LGD had 16 patients $(69.6 \%)$, and HGD/INV had 7 patients $(30.4 \%)$. The diagnostic accuracy of $C A R^{\text {high }}$ and each item was as follows: CAR high, AUC (0.64; 95\% CI, 0.42-0.86); MPD 5-9 mm, AUC (0.78; 95\% CI, 0.66-0.91); $5 \mathrm{~mm} / 2$ years increase, AUC (0.56; 95\% CI, 0.48-0.65); lymph node enlargement, AUC $(0.5 ; 95 \%$ CI, 0.50-0.50); wall thickening, AUC $(0.65 ; 95 \%$ CI, $0.44-0.87) ; 5 \mathrm{~mm}>$ nodule, AUC (0.55; 95\% CI, 0.34-0.76); $30 \mathrm{~mm}<$ cyst, AUC $(0.69 ; 95 \%$ CI, 0.47-0.91). The diagnostic accuracy of CAR high was not high, but it was improved by combining it with MPD 5-9 mm, AUC (0.84; 95\% CI, 0.70-0.99) (Figure 5). 


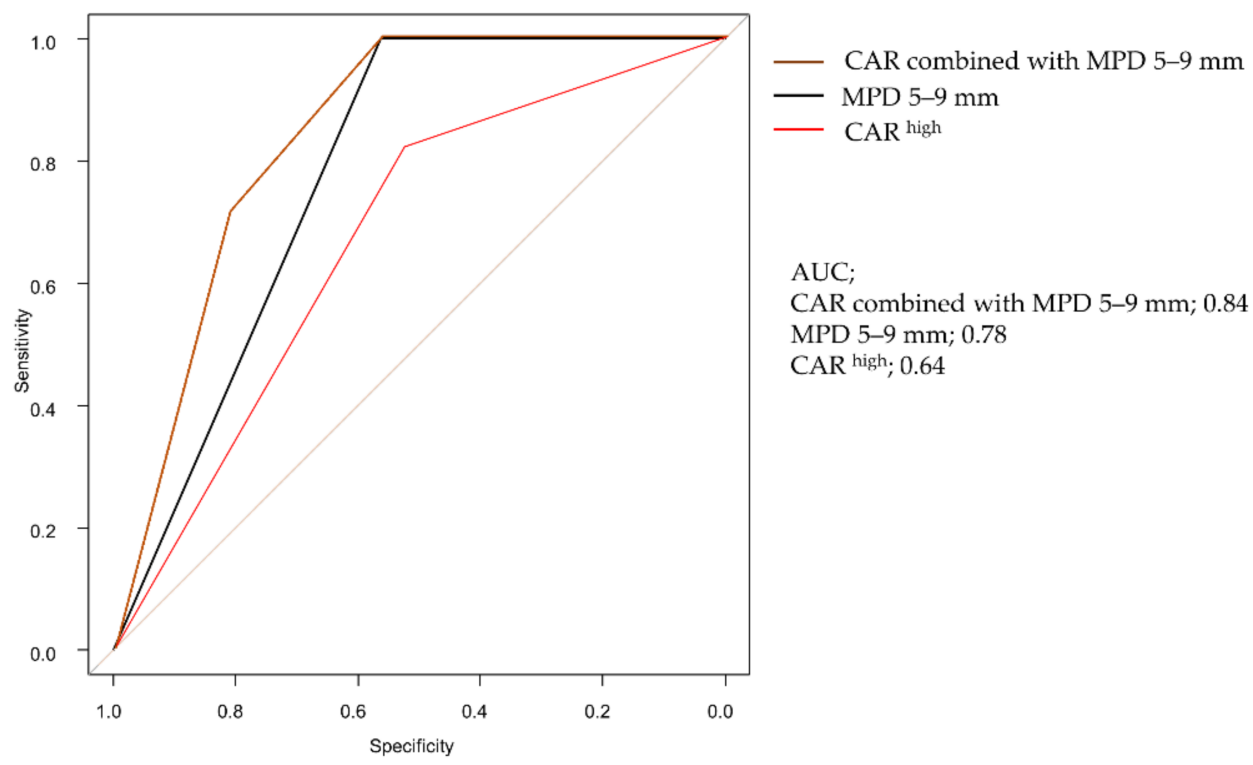

Figure 5. Receiver operating characteristics (ROC) curve for $C A R^{\text {high }}$ combined with Main pancreatic duct (MPD) 5-9 mm, MPD 5-9 mm and CAR high . CAR high combined with MPD 5-9 mm is 0.84 .

\section{Discussion}

We investigated the relationship between the preoperative inflammation-based scores and the malignant transformation of IPMN and found that the CAR ${ }^{\text {high }}(\geq 0.011)$ is a predictive factor for malignant transformation of IPMN. In addition, the analysis showed that a higher value of CAR positively correlates with the malignant transformation of IPMN. These results show that CAR can be used as a simple and clinically meaningful biomarker for the malignant transformation of IPMN.

It is widely known that host-tumor interaction between local cancer and an individual has a significant effect on their general condition, including cancer patients' nutritional status and immunocompetence. Patients with cancer often have systemic inflammation, and a combination of serum CRP and albumin level is used as a method for evaluating inflammatory response and nutritional status. McMillan et al. reported GPS to be an excellent prognostic marker for non-small cell lung cancer [21].

Many studies have also reported that GPS plays a pivotal role in the progression of various malignancies, and is closely related to poor prognosis in patients [22-26]. In recent years, CAR has also been reported to have clinical implications and usefulness in many studies, including research regarding pancreatic cancer [27-31]. Cancer patients have chronically increased Interleukin-6 (IL-6) in the circulating blood, affecting the acute-phase proteins (APPs); positive APP corresponds to CRP, and negative APP to albumin. Therefore, it is an index that indirectly indicates the presence of systemic metabolic abnormality derived from circulating IL-6 in cancer patients, independent of the clinical stage of cancer.

In addition, the association between NLR and invasive carcinoma of IPMN has been reported [17-19]. However, these studies did not related to predictive markers for the presence of cancer, including HGD. IPMN should be resected before progression to invasive carcinoma, because IPMN with associated invasive carcinomas has significantly poorer prognosis than that without invasion. We found CAR to be a predictive marker for the presence of cancer, including HGD, in IPMN patients. In the present study, we focused on patients with respectable IPMN rather than advanced cancer. Therefore, we performed predictions for those with mild systemic inflammation and good nutritional status, using CAR as the basis for evaluation. The median CAR was 0.02 (range 0.006-0.09), and there were no GPS2. The preoperative value of CAR $(\geq 0.011)$ was an independent predictive factor for the presence of HGD/INV in the univariate and multivariate analysis, and a higher CAR value further increased this likelihood. 
Previous studies have reported that higher inflammatory markers, including CAR, are associated with higher histological grades from LGD to HGD $[17,18]$. In these results, a minor host response of intraepithelial neoplastic changes leading to peripancreatic inflammatory cell infiltration and increased intracystic inflammation with cytokine production such as IL and prostaglandin are related. This suggests that systemic inflammation differs not only in INV, but also between LGD and HGD, supporting the present study.

In the present study, CAR high was correlated with significantly shorter DFS. The outcomes of patients with cancer were determined with respect to patient-related factors, and the presence of preoperative systemic response in patients have been reported to predict poor survival after resection of several gastrointestinal cancers [25,32,33]. In particular, the predictive value of the CAR has been reported to be superior to mGPS [27]. CAR was able to reflect the potential inflammatory state, and is believed to be able to lead to the prediction of DFS. In addition, the potential inflammatory state could be reflected in patients with WF. In our results, the diagnostic accuracy of CAR high was not high, but it was improved by combining it with MPD 5-9 mm.

The clinical implications of these study findings are that CAR can be used as a simple and objective biomarker for malignant transformation in patients with IPMN. Previous reports of NLR and PLR were able to predict INV, but not HGD. However, CAR was able to predict HGD and INV. We believe that the use of high-sensitivity CRP reflects minor changes that do not affect NLR or PLR. Therefore, high values of CAR will help predict the presence of cancer, including HGD, and transition to invasive examination such as ERCP and EUS. In addition, our results suggest that it could predict recurrence a short period of time before surgery. Since these results are able to predict the prognosis of patients with IPMN, we believe that they will contribute to study for improving prognosis in the future.

The major strength of the present study is that it is the first report describing the relationship between the preoperative value of CAR and the malignant transformation of IPMN. IPMN is difficult to diagnose in benign or malignancy without pathological results on image findings. EUS is the best inspectional method; however, the accuracy depends on the skill of the endoscopist. In addition, the evidence for the revisions in the IPMN International Consensus Guidelines 2017 is still unsatisfactory. In these situations, it is significant a relationship has been found with a biomarker capable of calculating the same value.

The present study has several limitations. First, this is based on retrospectively collected data in a single center. Second, this is a small sample. Therefore, this may cause the statistical power to be low, and selection bias to be present. Therefore, we used IPTW analysis. This method can adjust for confounding factors and evaluate causal effects without reducing the sample size using the estimated propensity scores to assign weights to the data. All included patients were histopathologically diagnosed with IPMN. However, we did not investigate the patients with IPMN without indication for resections. Third, some patients did not undergo EUS. EUS has been proven to be superior to CT/MRI for detecting pancreatic lesions. Therefore, preoperative evaluation of the mural nodules might be inadequate. However, in the revised IPMN International Clinical Practice Guidelines 2017, contrast-enhanced EUS is described as the best for the evaluation of mural nodules, but $\mathrm{CT} / \mathrm{MRI}$ is also acceptable, and clinical error is small. In the future, multicenter prospective studies with larger numbers of patients that include systemic inflammatory markers are needed to confirm the study results. In the results, systemic inflammatory markers might provide a possible clue for estimating the malignant transformation of IPMN.

\section{Conclusions}

The preoperative value of CAR is a predictive factor for the malignant transformation of IPMN, which increases with higher CAR. CAR can be used as a simple and clinically meaningful biomarker for malignant transformation of IPMN. 


\begin{abstract}
Author Contributions: Conceptualization, H.M.; methodology, H.M.; software, H.M.; formal analysis, H.M. and Y.N. (Yuji Nadatani); investigation, H.M., K.T. (Kojiro Tanoue), Y.I.-K., M.Y., A.H., G.O., K.K. and R.A.; data curation, Y.N. (Yuji Nadatani); writing-original draft preparation, H.M.; writing-review and editing, M.O., S.F., K.O., S.H., F.T., N.K., Y.N. (Yasuaki Nagami), K.T. (Koichi Taira) and Y.F.; supervision, Y.F.; project administration, Y.F. All authors have read and agreed to the published version of the manuscript.
\end{abstract}

Funding: This research received no external funding.

Institutional Review Board Statement: The study was conducted according to the guidelines of the Declaration of Helsinki, and approved by the Ethics Committee of the Osaka City University Graduate School of Medicine (protocol code 4342 and 19 July 2019).

Informed Consent Statement: Informed consent was obtained from all subjects involved in the study.

Conflicts of Interest: The authors declare no conflict of interest.

\title{
References
}

1. Tanaka, M. Clinical Management and Surgical Decision-Making of IPMN of the Pancreas. Methods Mol. Biol. 2019, 1882, 9-22. [CrossRef]

2. Werner, J.; Fritz, S.; Büchler, M.W. Intraductal papillary mucinous neoplasms of the pancreas-A surgical disease. Nat. Rev. Gastroenterol. Hepatol. 2012, 9, 253-259. [CrossRef]

3. Marchegiani, G.; Andrianello, S.; Pollini, T.; Caravati, A.; Biancotto, M.; Secchettin, E.; Bonamini, D.; Malleo, G.; Bassi, C.; Salvia, R. "Trivial" Cysts Redefine the Risk of Cancer in Presumed Branch-Duct Intraductal Papillary Mucinous Neoplasms of the Pancreas: A Potential Target for Follow-Up Discontinuation? Am. J. Gastroenterol. 2019, 114, 1678-1684. [CrossRef]

4. Tanaka, M.; Fernández-Del Castillo, C.; Kamisawa, T.; Jang, J.Y.; Levy, P.; Ohtsuka, T.; Salvia, R.; Shimizu, Y.; Tada, M.; Wolfgang, C.L. Revisions of international consensus Fukuoka guidelines for the management of IPMN of the pancreas. Pancreatology 2017, 17, 738-753. [CrossRef] [PubMed]

5. $\quad$ Oyama, H.; Tada, M.; Takagi, K.; Tateishi, K.; Hamada, T.; Nakai, Y.; Hakuta, R.; Ijichi, H.; Ishigaki, K.; Kanai, S.; et al. Longterm Risk of Malignancy in Branch-Duct Intraductal Papillary Mucinous Neoplasms. Gastroenterology 2020, 158, 226-237.e225. [CrossRef] [PubMed]

6. Jang, J.Y.; Kim, S.W.; Lee, S.E.; Yang, S.H.; Lee, K.U.; Lee, Y.J.; Kim, S.C.; Han, D.J.; Choi, D.W.; Choi, S.H.; et al. Treatment guidelines for branch duct type intraductal papillary mucinous neoplasms of the pancreas: When can we operate or observe? Ann. Surg. Oncol. 2008, 15, 199-205. [CrossRef] [PubMed]

7. Farrell, J.J. Editorial: Stopping Pancreatic Cyst Surveillance? Am. J. Gastroenterol. 2017, 112, 1162-1164. [CrossRef] [PubMed]

8. Yoshioka, T.; Shigekawa, M.; Yamai, T.; Suda, T.; Kegasawa, T.; Iwahashi, K.; Ikezawa, K.; Sakamori, R.; Yakushijin, T.; Hiramatsu, N.; et al. The safety and benefit of pancreatic juice cytology under ERCP in IPMN patients. Pancreatology 2016, 16, 1020-1027. [CrossRef]

9. Crippa, S.; Piccioli, A.; Salandini, M.C.; Cova, C.; Aleotti, F.; Falconi, M. Treatment of branch-duct intraductal papillary mucinous neoplasms of the pancreas: State of the art. Updates Surg. 2016, 68, 265-271. [CrossRef] [PubMed]

10. Coussens, L.M.; Werb, Z. Inflammation and cancer. Nature 2002, 420, 860-867. [CrossRef]

11. Sideras, K.; Braat, H.; Kwekkeboom, J.; van Eijck, C.H.; Peppelenbosch, M.P.; Sleijfer, S.; Bruno, M. Role of the immune system in pancreatic cancer progression and immune modulating treatment strategies. Cancer Treat. Rev. 2014, 40, 513-522. [CrossRef]

12. Templeton, A.J.; McNamara, M.G.; Šeruga, B.; Vera-Badillo, F.E.; Aneja, P.; Ocaña, A.; Leibowitz-Amit, R.; Sonpavde, G.; Knox, J.J.; Tran, B.; et al. Prognostic role of neutrophil-to-lymphocyte ratio in solid tumors: A systematic review and meta-analysis. J. Natl. Cancer Inst. 2014, 106, dju124. [CrossRef]

13. Goh, B.K.; Tan, D.M.; Chan, C.Y.; Lee, S.Y.; Lee, V.T.; Thng, C.H.; Low, A.S.; Tai, D.W.; Cheow, P.C.; Chow, P.K.; et al. Are preoperative blood neutrophil-to-lymphocyte and platelet-to-lymphocyte ratios useful in predicting malignancy in surgicallytreated mucin-producing pancreatic cystic neoplasms? J. Surg. Oncol. 2015, 112, 366-371. [CrossRef] [PubMed]

14. Arima, K.; Okabe, H.; Hashimoto, D.; Chikamoto, A.; Kuroki, H.; Taki, K.; Kaida, T.; Higashi, T.; Nitta, H.; Komohara, Y.; et al. The Neutrophil-to-Lymphocyte Ratio Predicts Malignant Potential in Intraductal Papillary Mucinous Neoplasms. J. Gastrointest. Surg. 2015, 19, 2171-2177. [CrossRef] [PubMed]

15. Kinoshita, A.; Onoda, H.; Imai, N.; Iwaku, A.; Oishi, M.; Fushiya, N.; Koike, K.; Nishino, H.; Tajiri, H. Comparison of the prognostic value of inflammation-based prognostic scores in patients with hepatocellular carcinoma. Br. J. Cancer 2012, 107, 988-993. [CrossRef] [PubMed]

16. Inoue, D.; Ozaka, M.; Matsuyama, M.; Yamada, I.; Takano, K.; Saiura, A.; Ishii, H. Prognostic value of neutrophil-lymphocyte ratio and level of $\mathrm{C}$-reactive protein in a large cohort of pancreatic cancer patients: A retrospective study in a single institute in Japan. Jpn. J. Clin. Oncol. 2015, 45, 61-66. [CrossRef]

17. Gemenetzis, G.; Bagante, F.; Griffin, J.F.; Rezaee, N.; Javed, A.A.; Manos, L.L.; Lennon, A.M.; Wood, L.D.; Hruban, R.H.; Zheng, L.; et al. Neutrophil-to-lymphocyte Ratio is a Predictive Marker for Invasive Malignancy in Intraductal Papillary Mucinous Neoplasms of the Pancreas. Ann. Surg. 2017, 266, 339-345. [CrossRef] 
18. Hata, T.; Mizuma, M.; Motoi, F.; Ishida, M.; Morikawa, T.; Takadate, T.; Nakagawa, K.; Hayashi, H.; Kanno, A.; Masamune, A.; et al. Diagnostic and Prognostic Impact of Neutrophil-to-Lymphocyte Ratio for Intraductal Papillary Mucinous Neoplasms of the Pancreas with High-Grade Dysplasia and Associated Invasive Carcinoma. Pancreas 2019, 48, 99-106. [CrossRef]

19. McIntyre, C.A.; Pulvirenti, A.; Lawrence, S.A.; Seier, K.; Gonen, M.; Balachandran, V.P.; Kingham, T.P.; D'Angelica, M.I.; Drebin, J.A.; Jarnagin, W.R.; et al. Neutrophil-to-Lymphocyte Ratio as a Predictor of Invasive Carcinoma in Patients with Intraductal Papillary Mucinous Neoplasms of the Pancreas. Pancreas 2019, 48, 832-836. [CrossRef]

20. Nagtegaal, I.D.; Odze, R.D.; Klimstra, D.; Paradis, V.; Rugge, M.; Schirmacher, P.; Washington, K.M.; Carneiro, F.; Cree, I.A.; the WHO Classification of Tumours Editorial Board. The 2019 WHO classification of tumours of the digestive system. Histopathology 2020, 76, 182-188. [CrossRef]

21. Forrest, L.M.; McMillan, D.C.; McArdle, C.S.; Angerson, W.J.; Dunlop, D.J. Evaluation of cumulative prognostic scores based on the systemic inflammatory response in patients with inoperable non-small-cell lung cancer. Br. J. Cancer 2003, 89, 1028-1030. [CrossRef] [PubMed]

22. McMillan, D.C.; Crozier, J.E.; Canna, K.; Angerson, W.J.; McArdle, C.S. Evaluation of an inflammation-based prognostic score (GPS) in patients undergoing resection for colon and rectal cancer. Int. J. Colorectal Dis. 2007, 22, 881-886. [CrossRef]

23. Dutta, S.; Crumley, A.B.; Fullarton, G.M.; Horgan, P.G.; McMillan, D.C. Comparison of the prognostic value of tumour- and patient-related factors in patients undergoing potentially curative resection of oesophageal cancer. World J. Surg. 2011, 35, 1861-1866. [CrossRef] [PubMed]

24. Knight, B.C.; Kausar, A.; Manu, M.; Ammori, B.A.; Sherlock, D.J.; O’Reilly, D.A. Evaluation of surgical outcome scores according to ISGPS definitions in patients undergoing pancreatic resection. Dig. Surg. 2010, 27, 367-374. [CrossRef] [PubMed]

25. Jamieson, N.B.; Denley, S.M.; Logue, J.; MacKenzie, D.J.; Foulis, A.K.; Dickson, E.J.; Imrie, C.W.; Carter, R.; McKay, C.J.; McMillan, D.C. A prospective comparison of the prognostic value of tumor- and patient-related factors in patients undergoing potentially curative surgery for pancreatic ductal adenocarcinoma. Ann. Surg. Oncol. 2011, 18, 2318-2328. [CrossRef] [PubMed]

26. La Torre, M.; Nigri, G.; Cavallini, M.; Mercantini, P.; Ziparo, V.; Ramacciato, G. The glasgow prognostic score as a predictor of survival in patients with potentially resectable pancreatic adenocarcinoma. Ann. Surg. Oncol. 2012, 19, 2917-2923. [CrossRef]

27. Haruki, K.; Shiba, H.; Shirai, Y.; Horiuchi, T.; Iwase, R.; Fujiwara, Y.; Furukawa, K.; Misawa, T.; Yanaga, K. The C-reactive Protein to Albumin Ratio Predicts Long-Term Outcomes in Patients with Pancreatic Cancer After Pancreatic Resection. World J. Surg. 2016, 40, 2254-2260. [CrossRef]

28. Wu, M.; Guo, J.; Guo, L.; Zuo, Q. The C-reactive protein/albumin ratio predicts overall survival of patients with advanced pancreatic cancer. Tumor Biol. 2016, 37, 12525-12533. [CrossRef] [PubMed]

29. Fan, Z.; Fan, K.; Gong, Y.; Huang, Q.; Yang, C.; Cheng, H.; Jin, K.; Ni, Q.; Yu, X.; Luo, G.; et al. The CRP/Albumin Ratio Predicts Survival and Monitors Chemotherapeutic Effectiveness in Patients with Advanced Pancreatic Cancer. Cancer Manag. Res. 2019, 11, 8781-8788. [CrossRef]

30. Liu, Z.; Jin, K.; Guo, M.; Long, J.; Liu, L.; Liu, C.; Xu, J.; Ni, Q.; Luo, G.; Yu, X. Prognostic Value of the CRP/Alb Ratio, a Novel Inflammation-Based Score in Pancreatic Cancer. Ann. Surg. Oncol. 2017, 24, 561-568. [CrossRef]

31. Murakawa, M.; Yamamoto, N.; Kamioka, Y.; Kamiya, M.; Kobayashi, S.; Ueno, M.; Morimoto, M.; Atsumi, Y.; Aoyama, T.; Tamagawa, H.; et al. Clinical Implication of Pre-operative C-reactive Protein-Albumin Ratio as a Prognostic Factor of Patients with Pancreatic Ductal Adenocarcinoma: A Single-institutional Retrospective Study. In Vivo 2020, 34, 347-353. [CrossRef] [PubMed]

32. Paramanathan, A.; Saxena, A.; Morris, D.L. A systematic review and meta-analysis on the impact of pre-operative neutrophil lymphocyte ratio on long term outcomes after curative intent resection of solid tumours. Surg. Oncol. 2014, $23,31-39$. [CrossRef] [PubMed]

33. Shirai, Y.; Shiba, H.; Sakamoto, T.; Horiuchi, T.; Haruki, K.; Fujiwara, Y.; Futagawa, Y.; Ohashi, T.; Yanaga, K. Preoperative platelet to lymphocyte ratio predicts outcome of patients with pancreatic ductal adenocarcinoma after pancreatic resection. Surgery $\mathbf{2 0 1 5}$ 158, 360-365. [CrossRef] [PubMed] 